\section{Military Technical College Kobry El-Kobbah, Cairo, Egypt}

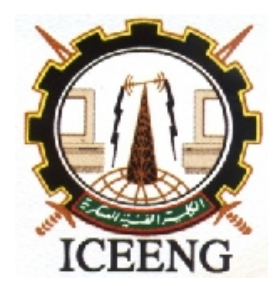

\title{
Analysis of false tripping for power transformers in Egypt
}

\author{
By
}
M. Abdelfatah*
M. EL-Shimy**1
H. M. Ismail**

\section{$\underline{\text { Abstract: }}$}

Frequent forced outages of power transformers can significantly affect the performance of industrial and commercial power systems and the processes they control. This paper presents the results of an extensive survey on false tripping of protection devices and systems for power transformers in Egypt. The outcomes of this work are beneficial in improving the design and maintenance of these protection systems to increase the reliability and availability of power systems. The data are obtained from the Egyptian Electricity Transmission Company (EETC). The collected data are in the form of transformer outage reports for eight years, from 2002 to 2009, where the average number of transformers is 1922 in voltage populations ranging from $33 \mathrm{kV}$ to $500 \mathrm{kV}$ and MVA rating from 5 MVA to 500 MVA. Results show that the fire-fighting systems are responsible for the highest number of false trips in all voltage sub-populations except the $220 \mathrm{kV}$ sub-population where the dominant cause of false trips is the bus bar protection.

\section{Keywords:}

Power transformers; protection systems; false tripping

* Electrical testing and transformers section, EETC. Ministry of Electricity, Cairo, Egypt.

** Electrical Power and Machines Department. Faculty of Engineering, Ain Shams University, Cairo, Egypt. P.O. Box (11517). ${ }^{1}$ Corresponding author: M. ELShimy; email: shimymb@gmail.com, Mob. 01005639589. 


\section{Introduction:}

Based on ANSI/IEEE C57.117-1986 [1], a transformer is a static electric device consisting of a winding or two or more coupled windings, with or without a magnetic core for introducing mutual coupling between electric circuits. Transformers can be classified to many types such as power transformers, autotransformers, regulating transformers.

High demands are imposed on power transformer protective relays. Requirements include dependability (no missing operations), security (no false tripping), and speed of operation (short fault clearing time) [2]. The operating conditions of power transformers do not make the relaying task easy. Protection of large power transformers is one of the most challenging problems in the power system relaying area. As shown in Fig. 1, the protection devices of the power transformer are split into electrical and mechanical protection [3]. Protection performance is generally classified into correct, no conclusion and incorrect operation. Incorrect operation may be either failure to trip or false tripping. No conclusion is the last resort when no evidence is available for correct or incorrect operation [2].

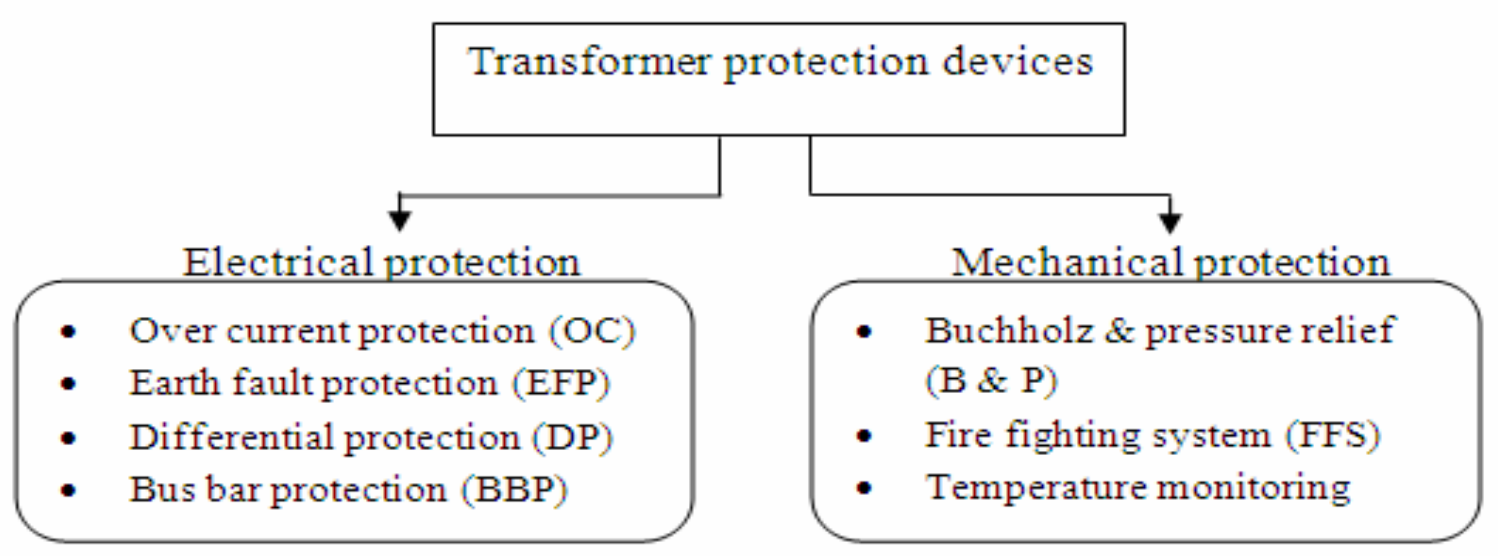

Figure (1): Transformer protection devices

The Egyptian Electricity Transmission Company (EETC) purchases bulk power from all generation entities and sells bulk power to the distribution companies and EHV/HV consumers [4]. The $500 \mathrm{kV}$ sub-population is considered the backbone of Egypt electrical network and includes thirteen nodes (substations), connected by $500 \mathrm{kV}$ transmission lines [5]. The $220 \mathrm{kV}$ sub-population in EETC plays a key role in transferring the power generated to other voltage levels, and considered one of the oldest transmission networks in comparison with many European countries $[6,8]$. The $132 \mathrm{kV}$ and $33 \mathrm{kV}$ networks are concentrated in Upper and Middle Egypt and considered as the oldest network in Egypt [4-7]. In 2009-2010, the total transformer capacities, as shown in Fig. 2, were 8515 MVA, 31978 MVA, 3451 MVA, 37741 
MVA, and $1806 \mathrm{MVA}$ for $500 \mathrm{kV}, 220 \mathrm{kV} 132 \mathrm{kV}, 66 \mathrm{kV}$, and $33 \mathrm{kV}$ networks respectively [7].

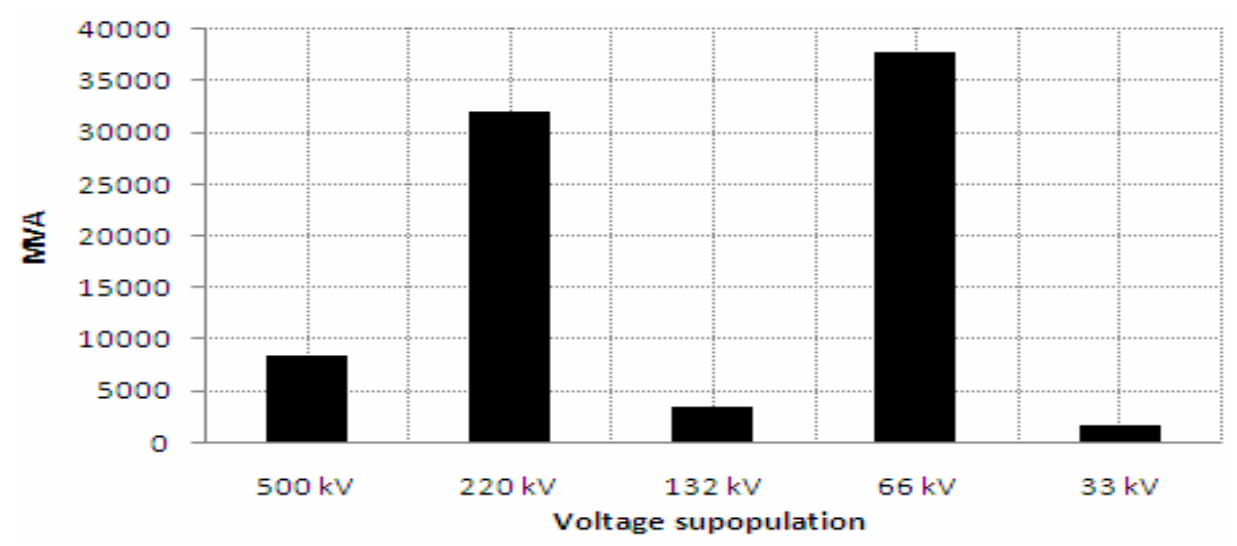

Figure (2): The EETC's total transformers capacities in 2009-2010

This paper presents the results of an extensive survey on false tripping of protection devices and systems for power transformers in Egypt. The data are obtained from the Egyptian Electricity Transmission Company (EETC). The collected data are in the form of transformer outage reports for eight years, from 2002 to 2009, where the average number of transformers is 1922 in voltage populations ranging from $33 \mathrm{kV}$ to $500 \mathrm{kV}$ and MVA rating from 5 MVA to 500 MVA.

\section{Outage Data Preparation:}

Outage reports of transformers in the voltage range of $33 \mathrm{kV}$ to $500 \mathrm{kV}$ from 2002 to 2009 are obtained from EETC. The collected data per outage include the transformer location, date and time, transformer outage duration, protection action, transformer restoration (or repair) time, interrupted MW and duration.

The total number of transformers in service was 1717 and 2124 in 2002 and 2009 respectively. Table 1 shows the actual and average numbers of transformers per voltage sub-population for years 2002 to 2009.

It is depicted from Fig. 2 that the installed capacity of the $33 \mathrm{kV}$ transformers in comparison with the $66 \mathrm{kV}$ transformers is small. In addition, the $33 \mathrm{kV}$ transformers are available only at Middle and Upper Egypt. Therefore, the $33 \mathrm{kV}$ and $66 \mathrm{kV}$ transformers are combined into a single voltage sub-population, a situation that is accepted and recommended by EETC because both the $66 \mathrm{kV}$ and $33 \mathrm{kV}$ transformers belong to the same authority. 
Proceedings of the $\boldsymbol{8}^{\text {th }}$ ICEENG Conference, 29-31 May, 2012

Table (1): Number of transformers per voltage sub-population During 2002 to 2009

\begin{tabular}{|c|c|c|c|c|c|}
\hline Year Subpopulation & $\mathbf{5 0 0} \mathbf{~ k V}$ & $\mathbf{2 2 0} \mathbf{~ k V}$ & $\mathbf{1 3 2} \mathbf{~ k V}$ & $\mathbf{6 6}-\mathbf{3 3 k V}$ & Total \\
\hline $\mathbf{2 0 0 2}$ & 30 & 223 & 85 & 1379 & 1717 \\
\hline $\mathbf{2 0 0 3}$ & 30 & 230 & 85 & 1422 & 1767 \\
\hline $\mathbf{2 0 0 4}$ & 30 & 234 & 83 & 1492 & 1839 \\
\hline $\mathbf{2 0 0 5}$ & 30 & 247 & 83 & 1541 & 1901 \\
\hline $\mathbf{2 0 0 6}$ & 30 & 251 & 87 & 1594 & 1962 \\
\hline $\mathbf{2 0 0 7}$ & 30 & 262 & 80 & 1633 & 2005 \\
\hline $\mathbf{2 0 0 8}$ & 30 & 274 & 81 & 1672 & 2057 \\
\hline $\mathbf{2 0 0 9}$ & 32 & 292 & 79 & 1721 & 2124 \\
\hline Average & 30 & 252 & 83 & 1557 & 1922 \\
\hline
\end{tabular}

\section{Performance Analysis of Protection Devices:}

An unplanned outage of a power transformer can cost electric utilities millions of dollars. Consequently, it is of great importance to minimize the frequency and duration of unwanted outages.

For the whole study period, Fig. 3 shows the percentages of false trips of protection devices/systems in various voltage sub-populations. The percentages of false trips are calculated as the number of false trips divided by the total number of trips.

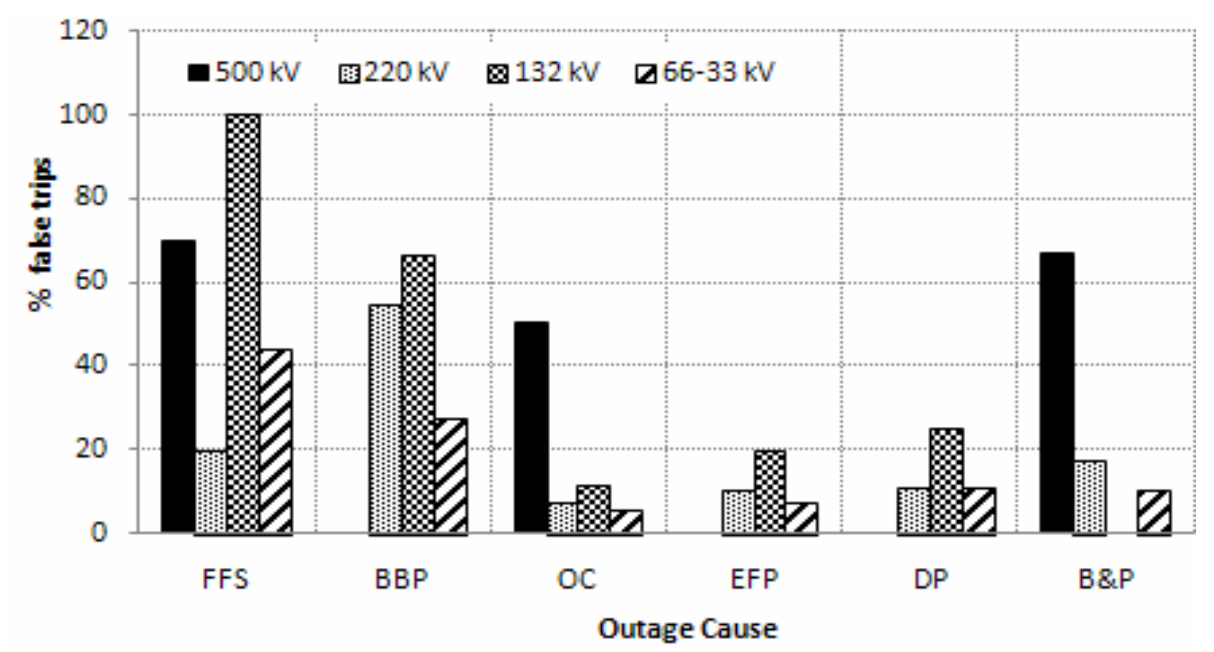

Figure (3): Percentages of false trips of protection devices in various voltage subpopulations

It is depicted from Fig. 3 that fire-fighting systems are responsible for the highest number of false trips in all voltage sub-populations except the $220 \mathrm{kV}$ sub-population 
where the dominant cause of false trips is the busbar protection. Busbar protection is also a significant cause of non-authentic outages in the $132 \mathrm{kV}$ and $66-33 \mathrm{kV}$ subpopulations. In the $500 \mathrm{kV}$ sub-population, a significant number of non-authentic outages is caused by over current protection and Buchholz and pressure relief.

It is found by investigation that the poor performance of fire-fighting systems is mainly due to improper maintenance of the compressed air line of these systems. In addition, it is found that lack of maintenance and testing of relays, and improper settings of protection devices are the main reasons of poor performance of busbar protection systems. Generally, false trips of protection systems can be significantly reduced by improving maintenance procedures, system monitoring, and operation strategies as well as revising the design of protection systems.

The contribution of false tripping of protection devices/systems in the outages of transformers over the years of the survey in percentages is illustrated in Fig. 4.

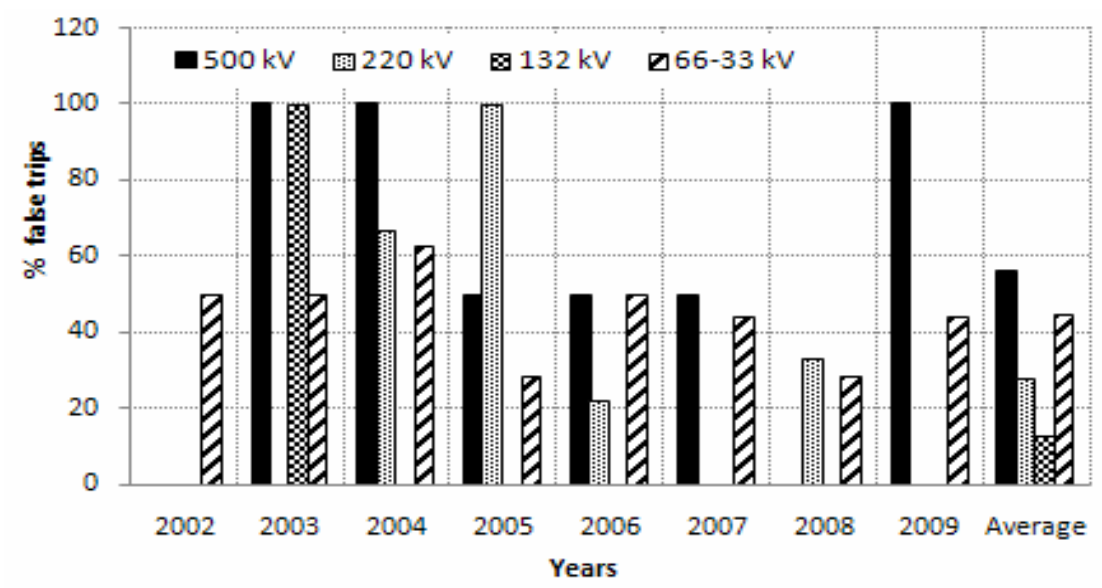

(a) Fire fighting system

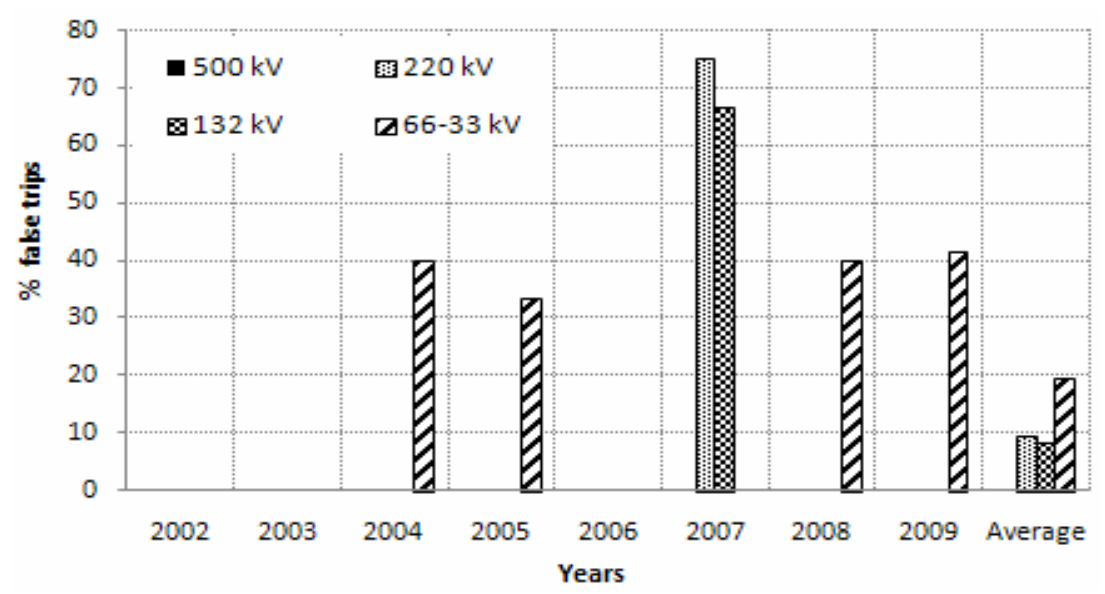

(b) Bus bar protection 
Proceedings of the $\boldsymbol{8}^{\text {th }}$ ICEENG Conference, 29-31 May, 2012

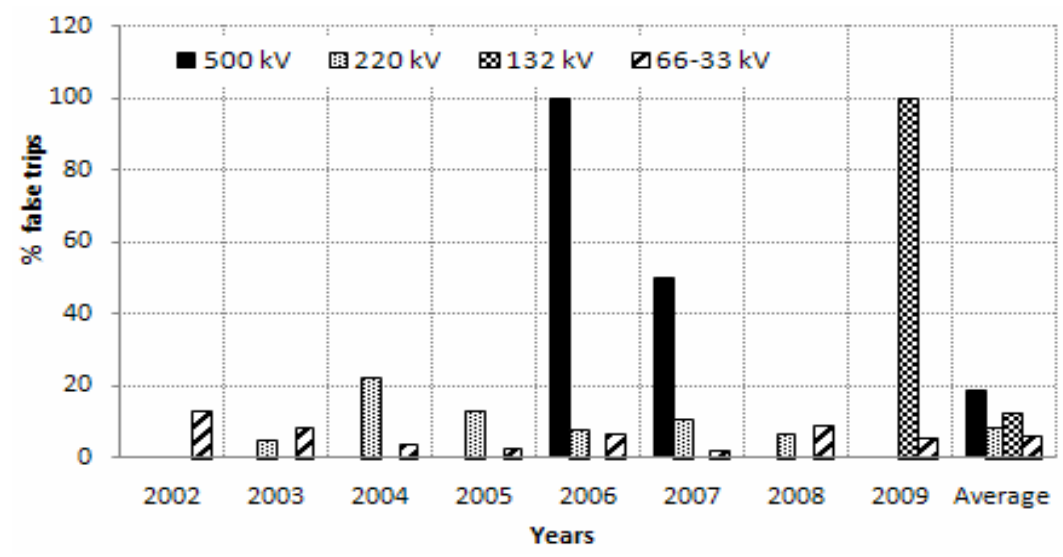

(c) Overcurrent protection

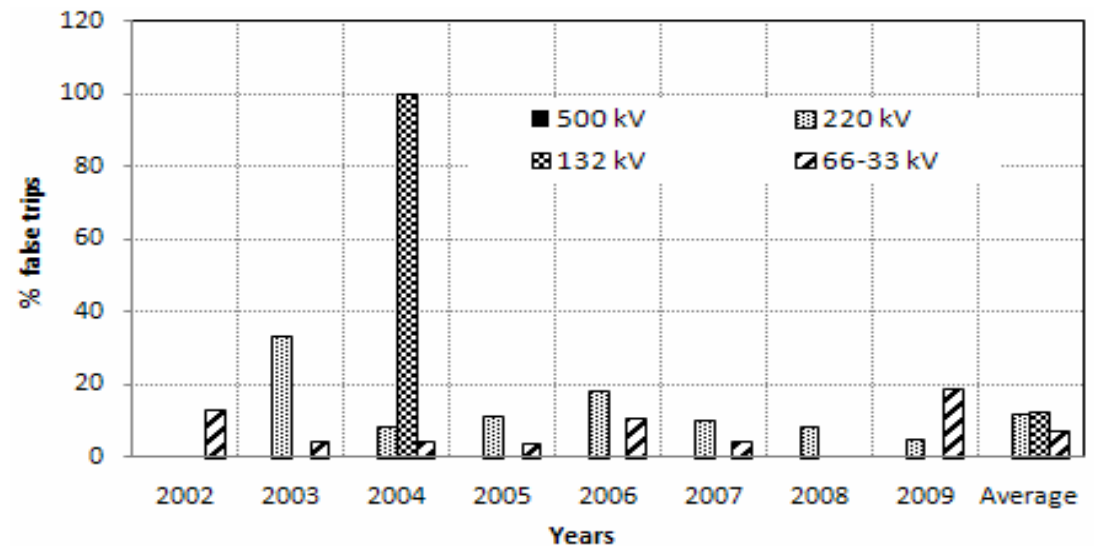

(d) Earth fault protection

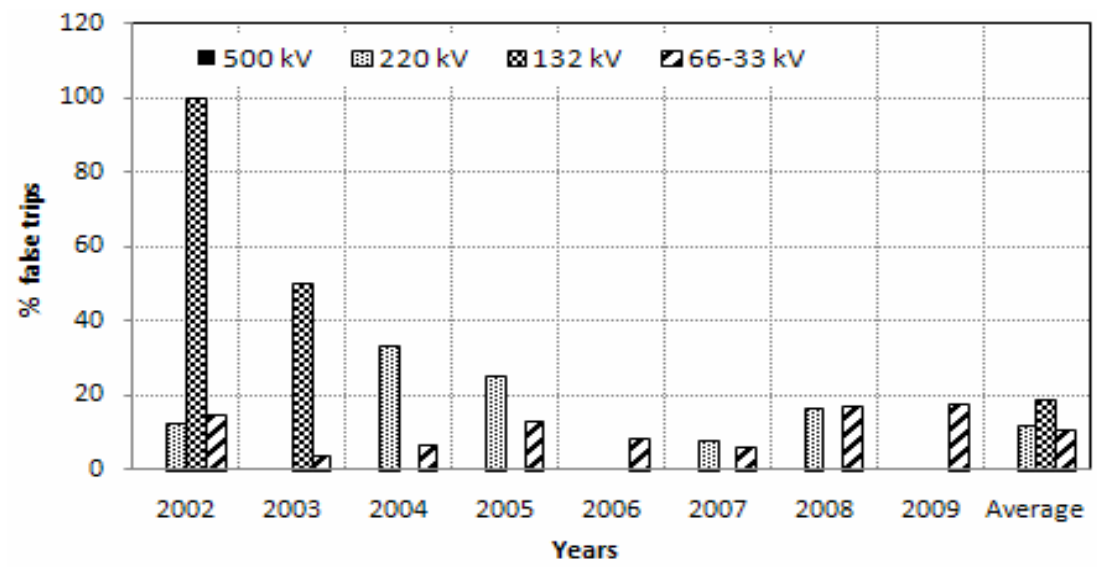

(e) Differential protection 


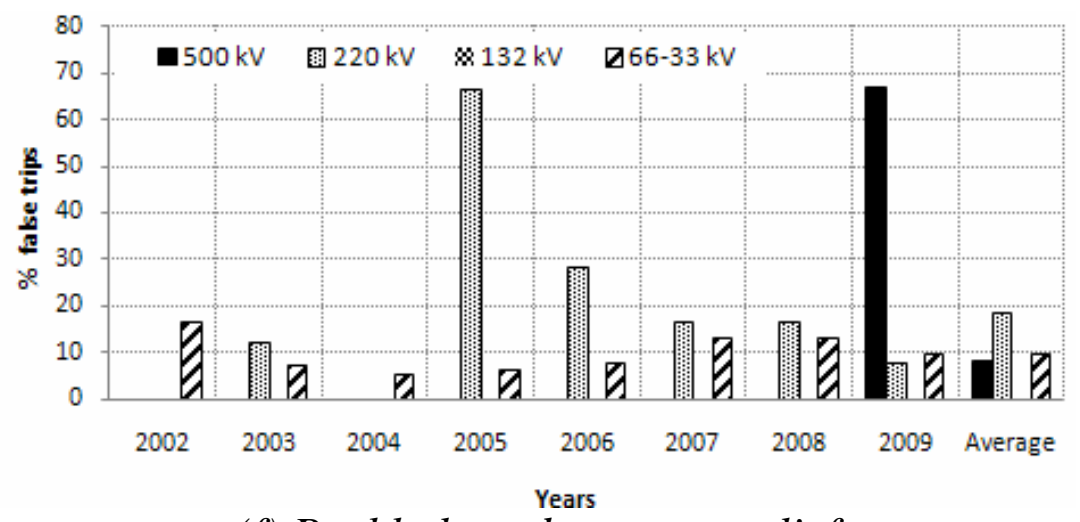

(f) Buchholz and pressure relief

Figure (4): percentages \& average of false trips of protection devices in various voltages versus year.

It is depicted from Fig. 4 that fire-fighting systems are the main contributors in the percentage average false trips of protection devices in all voltage sub-populations except the $132 \mathrm{kV}$ voltage sub-population where the dominant cause is the differential protection. In addition, it is clear from Fig. 4 that there are some healthy protective devices/systems (which did not contribute to false trips) in various voltage subpopulations. For the $500 \mathrm{kV}$ transformers these devices/systems are the bus bar protection (Fig. 4-b), earth fault protection (Fig. 4-d), and differential protection (Fig. 4e). In addition, Buchholz and pressure relief protection shows healthy behavior in the $132 \mathrm{kV}$ transformers (Fig. 4-f).

It is depicted from Fig. 4-a that the largest percentage average false trips of fire fighting systems occurred in the $500 \mathrm{kV}$ transformers followed by $66-33 \mathrm{kV}, 220 \mathrm{kV}$ and $132 \mathrm{kV}$ transformers respectively.

From the bus bar protection point of view, (Fig. 4-b), highest percentage average percentage false trips occurs in the $66-33 \mathrm{kV}$ transformers followed by $220 \mathrm{kV}$ and 132 $\mathrm{kV}$ transformers respectively. No false trips are associated with the bus bar protection in the $500 \mathrm{kV}$ transformers during the surveyed period.

As shown in Fig. 4-c, from over current protection point of view, the highest percentage average false trips is associated with the $500 \mathrm{kV}$ transformers followed by the $132 \mathrm{kV}, 220 \mathrm{kV}$, and $66-33 \mathrm{kV}$ transformers.

It is concluded from Fig. 4-d and Fig. 4-e that both earth fault and differential protection caused the largest average percentage of false trips in the $132 \mathrm{kV}$ transformers followed by the $220 \mathrm{kV}$, and $66-33 \mathrm{kV}$ transformers. In addition, these protective systems did not contribute to the false trips of the $500 \mathrm{kV}$ transformers during the surveyed period.

From Buchholz and pressure relief protection point of view, the highest percentage average false trips occur in the $220 \mathrm{kV}$ transformers followed by the $66-33 \mathrm{kV}$, and 500 
$\mathrm{kV}$ transformers as shown in Fig. 4-f. In addition, no records are associated with false trips of the Buchholz and pressure relief protection in the $132 \mathrm{kV}$ transformers.

\section{Conclusion:}

This paper presents the results of an extensive survey on false tripping of protection devices and systems for power transformers in Egypt.

It is found that the fire-fighting systems are responsible for the highest number of false trips in all transformers except the $220 \mathrm{kV}$ transformers where the dominant cause of false trips is the busbar protection. In addition, it is found that the fire fighting system is the main contributor in the average percentage of false trips of protection devices for all transformers during the surveyed period except the $132 \mathrm{kV}$ transformers where the dominant cause is the differential protection.

It is found by investigation that the poor performance of fire-fighting systems is mainly due to improper maintenance of the compressed air line of these systems. In addition, it is found that lack of maintenance and testing of relays, and improper setting of protection devices are the main reasons of poor performance of busbar protection systems. Generally, false trips of protection systems can be significantly reduced by improving maintenance procedures, system monitoring, and operation strategies as well as revising the design of protection systems. Therefore, it is recommended to improve the maintenance and design of protection systems especially the fire fighting systems in order to limit the false trips of power transformers.

For the $500 \mathrm{kV}$ transformers the healthy protective devices/systems (which did not contribute to false trips) are the bus bar protection, earth fault protection, and differential protection. In addition, Buchholz and pressure relief protection shows healthy behavior in the $132 \mathrm{kV}$ transformers.

\section{Acknowledgment:}

The authors would like to express their gratitude to the Egyptian Electricity Transmission Company (EETC) for their valuable discussions, data, and support.

\section{References:}

[1] IEEE Guide for Reporting Failure Data for Power Transformers and Shunt Reactors on Electric Utility Power Systems, ANSI/IEEE C57.117-1986.

[2] W. A. Elmore, Protective Relaying Theory, and Application, 2nd ed. New York: Marcel Dekker, 1994. 
[3] Protection Application Handbook, Revision 0, Sweden: ABB BU Transmission Systems and Substations, 1996.

[4] S. E. El-Arab, and H. Zarzoura, Reliability evaluation for the egyptian transmission and subtransmission networks, in Proc. Power Tech, Lausanne, P. 1723-1725, 2007.

[5] G. N. Alexandrov, and M. M. Dardeer, $500 \mathrm{kV}$ Transmission System in Egypt Solving Problem of Voltage Regulation By Means Of Controlled Shunt Reactor Transformer Type (CSRT), in Proc. 12th International Middle-East MEPCON 2008, Aswan, Egypt, P. 178-182, 2008.

[6] T. Dietermann, G. Balzer, and C. Neumann, The development in electricity exchanges and their impact on the German transmission system, in Proc. Power Tech., Lausanne, Switzerland, P. 12-16, 2007.

[7] Ministry of Electricity \& Energy. (2011). Annual report of EEHC 2009/2010 [Online]. Available: http://www.moee.gov.eg/English/e-fr-main.htm

[8] M. Abdelfatah, M. EL-Shimy, and H.M. Ismail, Reliability and Maintainability Analysis of $220 \mathrm{kV}$ Power Transformers in Egypt, Ain Shams Engineering Journal (ASEJ), Vol. 2, P. 183-194, 2011.

\section{Biographies}

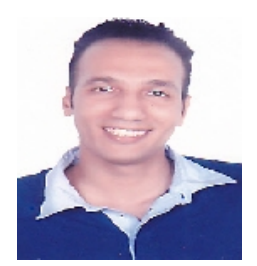

Mohamed Mahmoud Abdelfatah holds a B.Sc. in electric power and machines engineering from Ain Shams University. He is now a M.Sc. candidate at Ain Shams University. Since 2007 until now, he is working as a testing engineer for power transformers in EETC (Cairo zone).

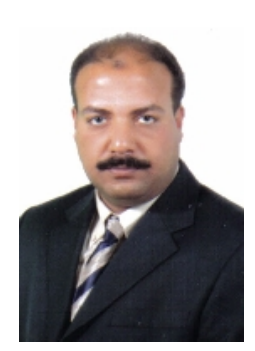

Mohamed EL-Shimy Mahmoud is currently an associate professor in the department of Electric Power and Machines - Faculty of Engineering - Ain Shams University. In addition, he is an electromechanical specialist, a freelance trainer and a member of many associations and professional networks. He is also a technical reviewer for some international journals and conferences. His fields of interest include power system analysis, power system economics, power system optimization, electric power distribution, renewable-energy resources and technologies, and power system reliability. For more details, please visit: http://shimymb.tripod.com 
and http://eg.linkedin.com/in/shimymb Tel.: +2 01005639589. (Corresponding author).

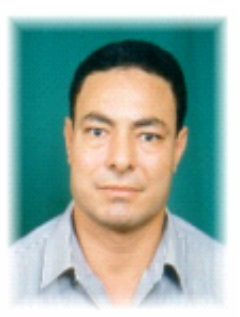

Hanafy Mahmoud Ismail was born in Cairo, Egypt, in 1956. He received the B.S. and M.S. degrees in electrical engineering from Electrical Engineering Department, Faculty of Engineering at Ain-Shams University, Cairo, in 1979 and 1984, respectively. He received the Ph.D. degree in 1989 from Electrical Engineering Department at the University of Windsor, Windsor, ON, Canada. Since graduation, he has been working at the Electrical Engineering Department, Faculty of Engineering, Ain-Shams University. He is now a Professor and deals mainly with the high voltage power transmission and their associated electrostatics and electromagnetic fields. He is also working in the area of power systems, underground cables, and fault detection on transmission lines. 